\title{
Editorial
}

\section{Search Engine Optimization}

\author{
Andreas Veglis 1,*(i) and Dimitrios Giomelakis 1,2 \\ 1 Media Informatics Lab, School of Journalism \& Mass Communications, Aristotle University of Thessaloniki, \\ 54124 Thessaloniki, Greece; dgiomela@jour.auth.gr \\ 2 Informatics and Telematics Institute (ITI) of the Centre of Research \& Technology Hellas (CERTH), 57001 \\ Thessaloniki, Greece \\ * Correspondence: veglis@jour.auth.gr
}

Received: 25 December 2019; Accepted: 31 December 2019; Published: 31 December 2019

check for updates

\section{Introduction}

The introduction of the World Wide Web (WWW), 25 years ago, has considerably altered the manner in which people obtain information. Soon after the introduction of the WWW, it was evident that traditional browsing was totally insufficient for internet users to locate the information that interests them. This need was covered with the development of search engines. Today, search engines play one of the most important roles in disseminating content. Search engine optimization (SEO) is a collection of strategies that improves a website's presence and visibility on a search engine's results page (SERP). In other words, the higher and more frequently a site appears in search results, the more visitors it will receive through the use of search engines. The importance of SEO can be understood by the fact that many web sites today receive the majority of their web traffic through a search engine's organic results.

The methods that SEO includes can be divided into four major categories: keyword research/selection, search engine indexing, on-page optimization, and off-page optimization. On-page optimization includes the management of all factors associated directly with someone's website (e.g., keywords, appropriate content, and internal link structure), while off-page optimization includes all the efforts made away from the website such as link building or social signal strategy. Undeniably, the world of search engine optimization has changed and evolved drastically over the years with a shift away from traditional ranking factors towards deeper analysis, and factors such as quality, multi-form content, and social signals. However, even though SEO has changed a lot, it remains an important part of any digital marketing strategy.

This special issue is soliciting theoretical and case studies contributions, discussing and treating challenges, state-of-the-art technology, and solutions on search engine optimization, including, but not limited to, the following themes related to SEO: Theory of SEO, different types of SEO, SEO criteria evaluation, search engines' algorithms, social media and SEO, SEO applications in various industries, SEO in media web sites, etc. Through invited and open call submissions, a total of five excellent articles have been accepted, following a rigorous review process that required a minimum of three reviews and at least one revision round for each paper.

\section{Contributions}

The first paper, written by Christos Ziakis, Maro Vlachopoulou, Theodosios Kyrkoudis, and Makrina Karagkiozidou [1], identifies the main factors that affect the ranking of a website in the search engines' results in order to provide enterprises and freelancers with a guide on the best techniques to maximize a website's position in search results. The paper consists of two parts. The first part performs a literature review through a collection and analysis of academic papers and the second part consists of research that was conducted manually using different phrases as case studies. 
Minos-Athanasios Karyotakis, Evangelos Lamprou, Matina Kiourexidou, and Nikos Antonopoulos are the authors of the second paper [2] that aims to expand the current literature about the SEO practices by focusing on examining, via the walkthrough method, the ways that news companies allow the users to comment on their online news articles. The study investigates an extensive sample of Greek, Cypriot, and international news websites.

The third paper written by Cristòfol Rovira, Lluís Codina, Frederic Guerrero-Solé, and Carlos Lopezosa [3] investigates academic SEO by analyzing and comparing the relevance ranking algorithms employed by various academic platforms in order to identify the importance of citations received in their algorithms. The authors analyze two search engines and two bibliographic databases: Google Scholar and Microsoft Academic, on the one hand, and Web of Science and Scopus, on the other.

Andreas Giannakoulopoulos, Nikos Konstantinou, Dimitris Koutsompolis, Minas Pergantis, and Iraklis Varlamis have contributed the fourth paper of the special issue [4]. The purpose of this paper is to study the extent to which a university's academic excellence is related to the quality of its web presence. The study deals with the website quality and search engine optimization (SEO) performance of the most well-known university websites, using the Academic Ranking of World Universities (ARWU) Shanghai list as a base of reference.

Finally, the fifth paper was written by Dimitrios Giomelakis, Christina Karypidou, and Andreas Veglis [5] includes an exploratory study on the use of search engine optimization (SEO) in news websites. Through a series of semi-structured interviews with SEO and media professionals at four Greek media organizations, the study examines the familiarity of these news publishers with SEO practices, including common trends and practices inside their own newsrooms, and the perceived impact of SEO on journalism and news content.

Conflicts of Interest: The authors declare no conflict of interest.

\section{References}

1. Ziakis, C.; Vlachopoulou, M.; Kyrkoudis, T.; Karagkiozidou, M. Important Factors for Improving Google Search Rank. Future Internet 2019, 11, 32. [CrossRef]

2. Karyotakis, M.-A.; Lamprou, E.; Kiourexidou, M.; Antonopoulos, N. SEO Practices: A Study about the Way News Websites Allow the Users to Comment on Their News Articles. Future Internet 2019, 11, 188. [CrossRef]

3. Rovira, C.; Codina, L.; Guerrero-Solé, F.; Lopezosa, C. Ranking by Relevance and Citation Counts, a Comparative Study: Google Scholar, Microsoft Academic, WoS and Scopus. Future Internet 2019, 11, 202. [CrossRef]

4. Giannakoulopoulos, A.; Konstantinou, N.; Koutsompolis, D.; Pergantis, M.; Varlamis, I. Academic Excellence, Website Quality, SEO Performance: Is there a Correlation? Future Internet 2019, 11, 242. [CrossRef]

5. Giomelakis, D.; Karypidou, C.; Veglis, A. SEO inside Newsrooms: Reports from the Field. Future Internet 2019, 11, 261. [CrossRef] 